\title{
Effect of lactic acid and lysozyme on river fish fillets during cold storage
}

\author{
LIEN LE PHUONG NGUYEN ${ }^{1,2 *}$ (1)
}

\footnotetext{
${ }^{1}$ Institute of Food Science and Technology, Hungarian University of Agriculture and Life Sciences, 1118 Budapest, Hungary

${ }^{2}$ Institute of Biotechnology and Food Technology, Industrial University of Ho Chi Minh City, Ho Chi Minh, Viet Nam
}

\section{CONFERENCE FULL PAPER}

Received: June 11, 2021 • Accepted: August 12, 2021

Published online: August 31, 2021

(C) 2021 The Author(s)

\begin{abstract}
Presented work evaluated how quality of catfish fillets is affected by treatments using lactic acid or lysozyme in combination with chlorine. Fish fillets without skin were consecutively immersed and washed in $100 \mathrm{ppm}$ chlorine solution and sprayed with $2.5 \%$ lactic acid or $0.5 \%$ lysozyme solution. Control samples were only washed with water at the same time. Samples were stored at $2{ }^{\circ} \mathrm{C}$ for 10 days in vacuum packaging. Parameters of $\mathrm{pH}$, firmness, surface color and microbial cell counts (cfu/g) were measured on the $1^{\text {st }}, 4^{\text {th }}, 7^{\text {th }}$ and $10^{\text {th }}$ days. Especially the latter had high importance from the point of view of food safety. Catfish fillets shown decreased survival of microorganisms as a result of treatment. Lysozyme and lactic acid achieved 1.8 and $2.4 \mathrm{log}$ cfu/g reduction, respectively. Lower cell counts were observed for all treated samples compared to control during 10 days. Chlorine in combination with lactic acid achieved the best efficiency. The results are promising and suggest that combined treatment is able to improve safety by controlling microorganisms on fish fillets during cold storage.
\end{abstract}

\section{KEYWORDS}

catfish, chlorine, storage, microorganism

\footnotetext{
*Corresponding author. E-mail: Nguyen.Le.Phuong.Lien@uni-mate.hu
} 


\section{INTRODUCTION}

Channel catfish (Ictalurus punctatus) is a popular freshwater fish providing key animal proteins for humans (Orban et al., 2008). In addition, catfish is also a vital source of minerals, vitamins, fatty acids and essential supplement for child growth and adult health (Ahmed et al., 2015). Besides the health benefits, fish has been involved in foodborne diseases due to microbial contamination (Kim and Marshall, 2001). Studies proved that fishes are continuously exposed in nature to a wide range of microorganisms, particularly in water and their feed (Ringø and Gatesoupe, 1998). Additionally, minimally processed food might be infected in the supply chain as well (Hasani et al., 2020; Kim and Marshall, 2001). According to recent studies in the topic, there is high demand for standard protocols preventing severe contamination and maintaining quality as long as possible (Nogueira et al., 2019; Park et al., 2017). Bonilla et al. (2018) successfully used $0.5 \%$ chitosan solution with $1 \%$ acetic acid to prolong microbiological shelf life of refrigerated catfish fillet. Lactic acid, $2 \%$ solution, and Lactococcus lactis spp. cremoris culture were found to suppress gram-negative bacteria on catfish fillet surface alone and in combination as well (Kim et al., 1995). Collagen-lysozyme was found to be effective in suppressing bacteria on salmon (Wang et al., 2017). Lysozyme, $0.5 \%$ solution, was able to reduce surface spoilage of carp (Palotás et al., 2020).

Therefore, the aim of this study was to investigate the effect of the combination of chlorine with lysozyme or lactic acid in decreasing microorganisms on catfish fillets during storage.

\section{MATERIALS AND METHODS}

\section{Materials}

Channel catfish (I. punctatus) were bought from a local catfish plant. On the same day, catfish were deboned and skinned. Fillets of catfish cut into 700-800 g pieces were immersed and washed in $100 \mathrm{ppm}$ chlorine solution for $60 \mathrm{~s}$, followed by $2.5 \%$ lactic acid or $0.5 \%$ lysozyme solution treatment as spray on the surface. Chlorine from electrolyzed water of $280 \mathrm{ppm}$ solution (Fishmarket Kft., Budaörs, Hungary) was diluted for treatment. Chlorine concentration was tested by instrument (Hanna Instrument, HI93701-0, Romania). Lysozyme stock solution was diluted with distilled water to obtain $0.5 \%$ concentration. Treatment was performed at $20^{\circ} \mathrm{C}$. Control samples were washed only with tap water. Samples were stored at $2{ }^{\circ} \mathrm{C}$ with ice flakes for $10 \mathrm{~d}$ using vacuum packaging made of $90 \mu \mathrm{m}$ thick polypropylene foil.

\section{Measurements}

Measurements were carried out on the $1^{\text {st }}, 4^{\text {th }}, 7^{\text {th }}$ and $10^{\text {th }}$ days. Three packages of each group were removed from the fridge to analyze the quality indices of catfish fillets for each storage interval.

Surface color. Surface color of catfish was measured with a handheld Minolta Chroma Meter CR-400 (Minolta Corporation, Osaka, Japan). Standard CIE L* $\mathrm{a}^{*}$ and $\mathrm{b}^{*}$ color characteristics were determined at three points on each fillet following Dam et al. (2020a, 2020b).

Drip loss. The drip loss from fillets was determined by the amount of liquid accumulated in the packages at each storage interval and calculated as the weight of liquid in the packages divided by initial weight of catfish fillets multiplied by 100 . 
Firmness. Firmness of fillet was determined by the maximum force required to penetrate each slice, using Stable Micro System TA-XT Plus, UK. All fillet slices were punctured at 6 locations to a depth of $15 \mathrm{~mm}$ using a $\varnothing 2 \mathrm{~mm}$ round-surfaced cylindrical probe with $2 \mathrm{~mm} \mathrm{~s}$ speed. The average of those six measurements was considered as one replicate. Results were expressed as $\mathrm{N}$.

$\mathrm{pH}$. $\mathrm{pH}$ of samples was measured at three points on each piece with a portable $\mathrm{pH}$ meter (Testo 206-pH1) by touching the electrode directly to the catfish fillet surface. Average $\mathrm{pH}$ values were reported from triplicate readings of each piece.

Microbiological analysis. Microbiological tests were carried out on day 0 (after treatment), and on the $1^{\text {st }}, 4^{\text {th }}, 7^{\text {th }}, 9^{\text {th }}$ and $10^{\text {th }}$ days. Fish fillets were blended for 2 min and appropriate serial dilutions were plated on agar media according to Kim et al. (1995). Total viable counts (TVC) were determined following the standard procedure of ISO 4833-1:2013 after $72 \mathrm{~h}$ incubation on plate count agar at $30^{\circ} \mathrm{C}$.

\section{Statistical analysis}

The software of IBM SPSS Statistics (IBM Inc, USA) was used to perform analysis of variances (ANOVA). Tukey's post-hoc test was applied to compare groups with $P<0.05$ significance level. Data are reported on charts with mean and standard deviation.

\section{RESULTS}

The surface $\mathrm{pH}$ of catfish fillets increased during the $10 \mathrm{~d}$ storage period. The $\mathrm{pH}$ value of fish samples treated with chlorine-lactic acid was lower than that of chlorine-lysozyme and control groups, probably due to the effect of lactic acid (Fig. 1). This observation is likely the result of production of alkaline substances of endogenous enzymes and bacteria, such as ammonia and trimethylamine (Cao et al., 2021).

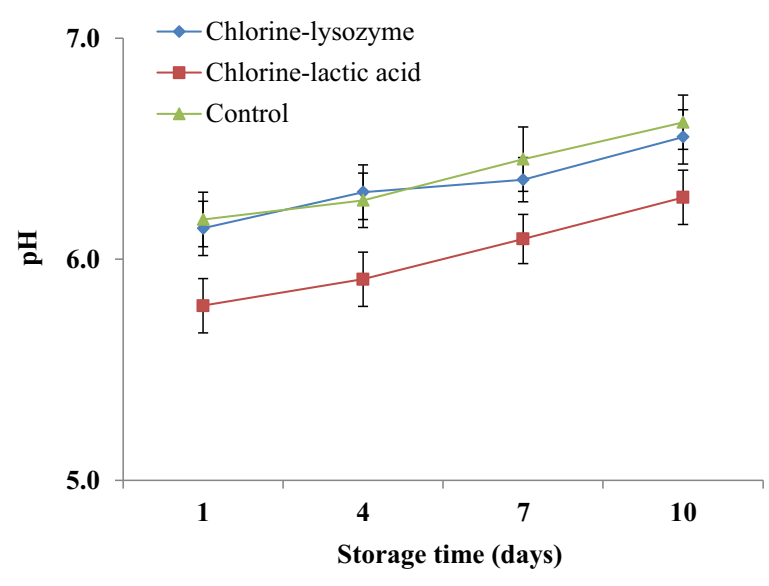

Fig. 1. $\mathrm{pH}$ of catfish fillet during storage 
The firmness of catfish fillets declined during $10 \mathrm{~d}$ of storage (Fig. 2). The control had the lowest value in firmness compared to other treatments. However, no significant effect of treatment was observed on firmness.

The drip loss of fish fillets increased throughout storage. Drip loss is consisting of loosely bound water and soluble substances, as a result of ruptured structure, protein degradation and rigor state (Cao et al., 2021). No significant difference was observed among samples. Drip loss was approximately $2.7 \%$ at the end of the experiment (Fig. 3).

The surface color of catfish fillets changed during storage (data not shown). Samples treated with lactic acid were lighter than the other samples (Fig. 4).

Treatment with lactic acid had negative effect on sensory attributes, lactic acid caused flesh discoloration. This was coincident with a previous report (Marshall and Kim, 1996).

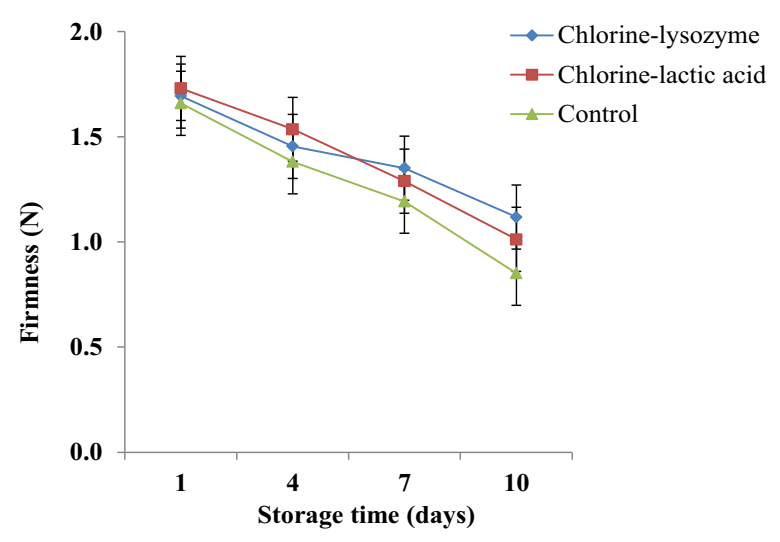

Fig. 2. Firmness of catfish fillet during storage

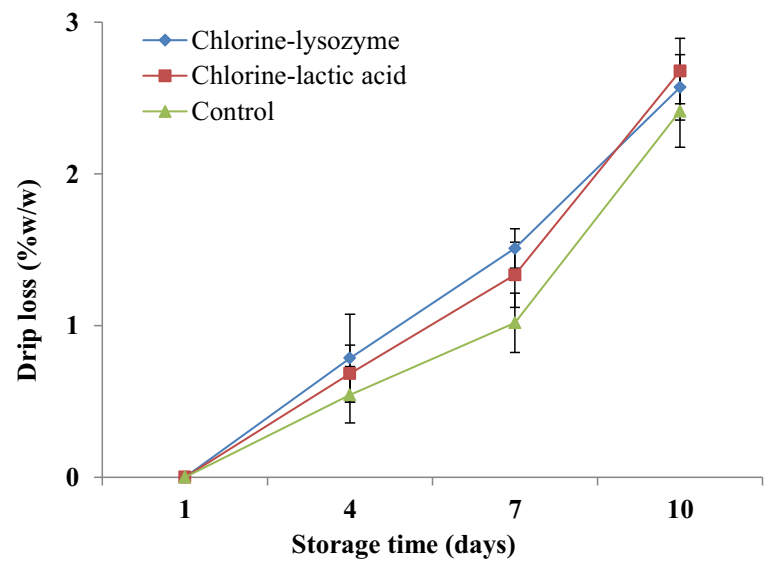

Fig. 3. Drip loss of catfish fillet during storage 


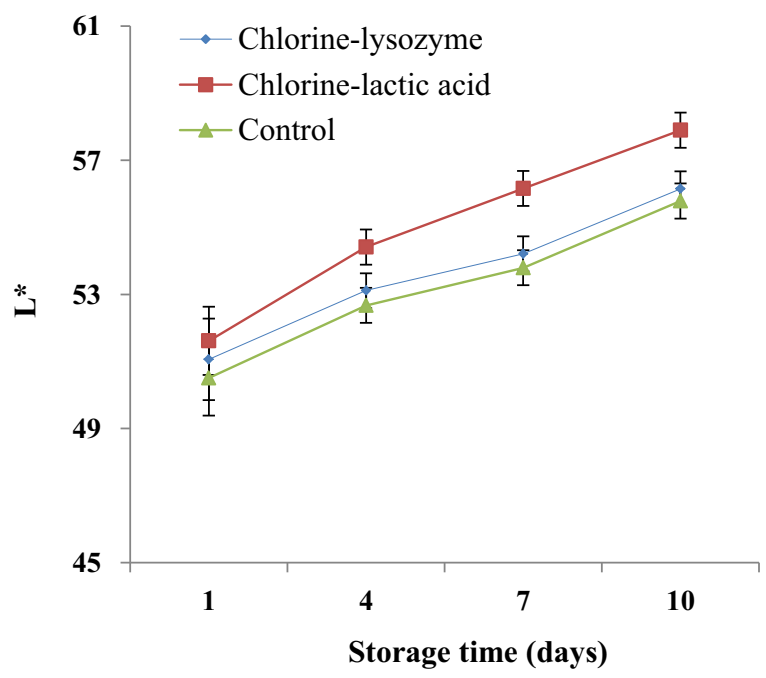

Fig. 4. $\mathrm{L}^{*}$ value of catfish fillet during storage

Figure 5 showed that chlorine-lysozyme and chlorine-lactic acid had benefit in controlling the level of microorganisms on fish fillets during storage. Treatment with chlorine-lysozyme and chlorine-lactic acid reduced the contamination by $1.8 \log \mathrm{cfu} \mathrm{g}^{-1}$ and $2.4 \log \mathrm{cfu} \mathrm{g}^{-1}$, respectively, compared to control.

At the end of the experiment, the differences between treatments were still significant. Fish treated with chlorine-lactic acid had the lowest number of microorganisms, compared to chlorine-lysozyme and control group. Lactic acid was effective in reducing the initial counts and growth of microorganisms during storage. This was in agreement with earlier reports (Kim et al., 1995; Kim and Marshall, 2001; Verhaegh et al., 1996).

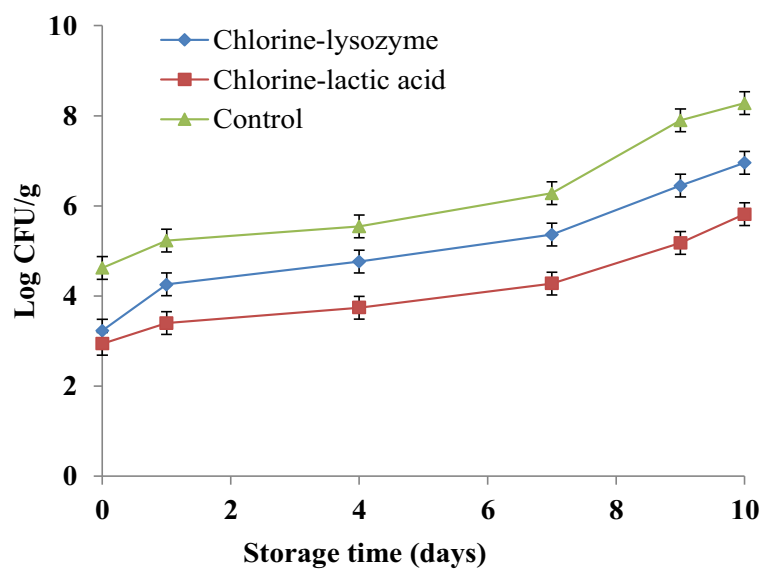

Fig. 5. Total viable counts of catfish fillet during storage 


\section{CONCLUSION}

The results of this study indicated that chlorine-lactic acid or chlorine-lysozyme treatment could maintain the quality of catfish fillets during cold storage. There was no significant difference in drip loss and firmness between treated samples and control. The surface color of fish fillet treated with lactic acid became lighter. However, treatment with chlorine-lactic acid or chlorinelysozyme benefited decreased microbial contamination of catfish fillets.

\section{ACKNOWLEDGEMENT}

The project was supported by the European Union and co-financed by the European Social Fund (grant agreement no. EFOP-3.6.3-VEKOP-16-2017-00005).

\section{REFERENCES}

Ahmed, M.K., Shaheen, N., Islam, M.S., Habibullah-al-Mamun, M., Islam, S., Mohiduzzaman, M., and Bhattacharjee, L. (2015). Dietary intake of trace elements from highly consumed cultured fish (Labeorohita, Pangasius pangasius and Oreochromis mossambicus) and human health risk implications in Bangladesh. Chemosphere, 128: 284-292.

Bonilla, F., Chouljenko, A., Reyes, V., Bechtel, P.J., King, J.M., and Sathivel, S. (2018). Impact of chitosan application technique on refrigerated catfish fillet quality. LWT, 90: 277-282.

Cao, L., Huang, Z., Wu, D., Ruan, R., and Liu, Y. (2021). Rapid and nondestructive determination of qualities in vacuum-packaged catfish (Clarias leather) fillets during slurry ice storage. Journal of Food Processing and Preservation, 45(3): e15262.

Dam, M.S., Nguyen, L.L.P., Zsom, T., Hitka, G., Zeke, I.C., and Friedrich, L. (2020a). Effect of perforation packaging on quality of fresh-cut carrot during storage, Progress in Agricultural Engineering Sciences, 16(S1): 11-18.

Dam, M.S., To, X.T., Le, Q.T.P., Nguyen, L.L.P., Friedrich, L., Hitka, G., Zsom, T., Nguyen, T.C.T., Huynh, C.Q., Tran, M.D.T., and Nguyen, V.D. (2020b). Postharvest quality of hydroponic strawberry coated with chitosan-calcium gluconate, Progress in Agricultural Engineering Sciences, 16(S2): 141-151.

Hasani, E., Labidi, S., Mohácsi-Farkas, C., and Kiskó, G. (2020). Comparison of biofilm formation between non-pathogenic Listeria strains under different stress conditions, Progress in Agricultural Engineering Sciences, 16(S2): 73-80.

Kim, C.R., Hearnsberger, J.O., and Eun, J.B. (1995). Gram-negative bacteria in refrigerated catfish fillets treated with lactic culture and lactic acid. Journal of Food Protection, 58(6): 639-643.

Kim, J. and Marshall, D.L. (2001). Effect of lactic acid on Listeria monocytogenes and Edwardsiella tarda attached to catfish skin. Food Microbiology, 18(6): 589-596.

Marshall, D.L. and Kim, C.R. (1996). Microbiological and sensory analyses of refrigerated catfish fillets treated with acetic and lactic acids. Journal of Food Quality, 19(4): 317-329.

Nogueira, B., Belusso, A.C., Breda, L.S., Oldoni, T., and Mitterer-Daltoé, M.L. (2019). Description and discrimination of freshness and biometric qualities of three different fishes: Grass carp, pacu, and catfish. Acta Alimentaria, 48(3): 341-348. 
Orban, E., Nevigato, T., Lena, G.D., Masci, M., Casini, I., Gambelli, L., and Caproni, R. (2008). New trends in the seafood market. Sutchi catfish (Pangasius hypophthalmus) fillets from Vietnam: nutritional quality and safety aspects. Food Chemistry, 110(2): 383-389.

Palotás, P., Jónás, G., Lehel, J., and Friedrich, L. (2020). Preservative effect of novel combined treatment with electrolyzed active water and lysozyme enzyme to increase the storage life of vacuum-packaged carp. Journal of Food Quality, 2020: 7.

Park, M.S., Kim, H.N., and Bahk, G.J. (2017). The analysis of food safety incidents in South Korea, 19982016. Food Control, 81: 196-199.

Ringø, E. and Gatesoupe, F.-J. (1998). Lactic acid bacteria in fish: a review. Aquaculture, 160(3): 177-203. Verhaegh, E.G.A., Marshall, D.L., and Oh, D.-H. (1996). Effect of monolaurin and lactic acid on Listeria monocytogenes attached to catfish fillets. International Journal of Food Microbiology, 29(2): 403-410.

Wang, Z., Hu, S., Gao, Y., Ye, C., and Wang, H. (2017). Effect of collagen-lysozyme coating on freshsalmon fillets preservation. $L W T, 75: 59-64$.

Open Access. This is an open-access article distributed under the terms of the Creative Commons Attribution 4.0 International License (https://creativecommons.org/licenses/by/4.0/), which permits unrestricted use, distribution, and reproduction in any medium, provided the original author and source are credited, a link to the CC License is provided, and changes - if any - are indicated. (SID_1) 